\title{
The challenges of implementing a "patient-oriented" telepathology network; the Eastern Québec telepathology project experience
}

\author{
Bernard Têtu ${ }^{\mathrm{a}, *}$, Jean-Paul Fortin ${ }^{\mathrm{b}}$, Marie-Pierre Gagnon ${ }^{\mathrm{c}}$ and Said Louahlia ${ }^{\mathrm{d}}$ \\ ${ }^{a}$ RUIS-Laval University telepathology project, Faculty of Medicine, Laval University, \\ Québec, Canada \\ ${ }^{\mathrm{b}}$ Department of Social and Preventive Medicine, Faculty of Medicine, Laval University, Québec, Canada \\ ${ }^{\mathrm{c}}$ Faculty of Nursing Sciences, Laval University, Québec, Canada \\ ${ }^{\mathrm{d}}$ Centre Hospitalier Régional de Baie-Comeau, Québec, Canada
}

\begin{abstract}
Background: The aim of the Eastern Québec telepathology project is to provide uniform diagnostic telepathology services across a huge geographic region with a low population density. This project is intended to provide surgeons and pathologists with frozen section and second opinion services anywhere and at any time across the entire region in order to avoid unnecessary patient transfer.

Methods: The project has been implemented in 21 sites, each equipped with a whole slide scanner, a macroscopy station, two videoconferencing devices and a viewer/case management and collaboration solution. Of the 21 sites, 6 are devoid of a pathology laboratory. Of the remaining 15 sites, two have no pathologists, 6 have one and 7 have two or more.

Results: The project has been successful and most appreciated by pathologists and surgeons. We report a number of challenges related to change management that we had to take into account in the course of implementation of this network. The challenges underscore the need for regular visits and active support to participating centers by the project team.

Conclusion: The Eastern Québec telepathology network is successful and improves medical care in this region. In the course of implementation, we encountered a number of challenges which required innovative solutions.
\end{abstract}

Keywords: Telepathology, digital pathology, Eastern Quebec telepathology network, whole-slide imaging

\section{Background}

Canada is a huge country with a low population density. In April 2011, 34,349,200 people were living in a region spanning 9,1 million $\mathrm{km}^{2}$ [18]. The province of Québec is the largest but the second most populated province with its $7,957,600$ inhabitants spread over

\footnotetext{
${ }^{*}$ Corresponding author: Bernard Têtu, MD, Service d'anatomopathologie et de cytologie, Centre Hospitalier Affilié Universitaire de Québec, 1050 Chemin Ste-Foy, Québec, G1S 4L8, Canada. Tel.: +1 418682 7511, Ext.: +1 2592; E-mail: bernard.tetu@fmed.ulaval.ca.
}

1,7 million $\mathrm{km}^{2}$ [18]. In 2003, the "University Integrated Health Networks" (in French: RUIS: Réseaux Universitaires Intégrés en Santé) [17] were created as a body of coordination and consensus whose mandate is to encourage the integration of health care, teaching and research activities in the institutions under the umbrella of a faculty of medicine. There are four faculties of medicine in Québec and, therefore, 4 RUIS were created (Fig. 1). The Laval University RUIS spans over $452,600 \mathrm{~km}^{2}$ in which 1.7 million inhabitants live. In certain areas, the density is as low as 0.4 


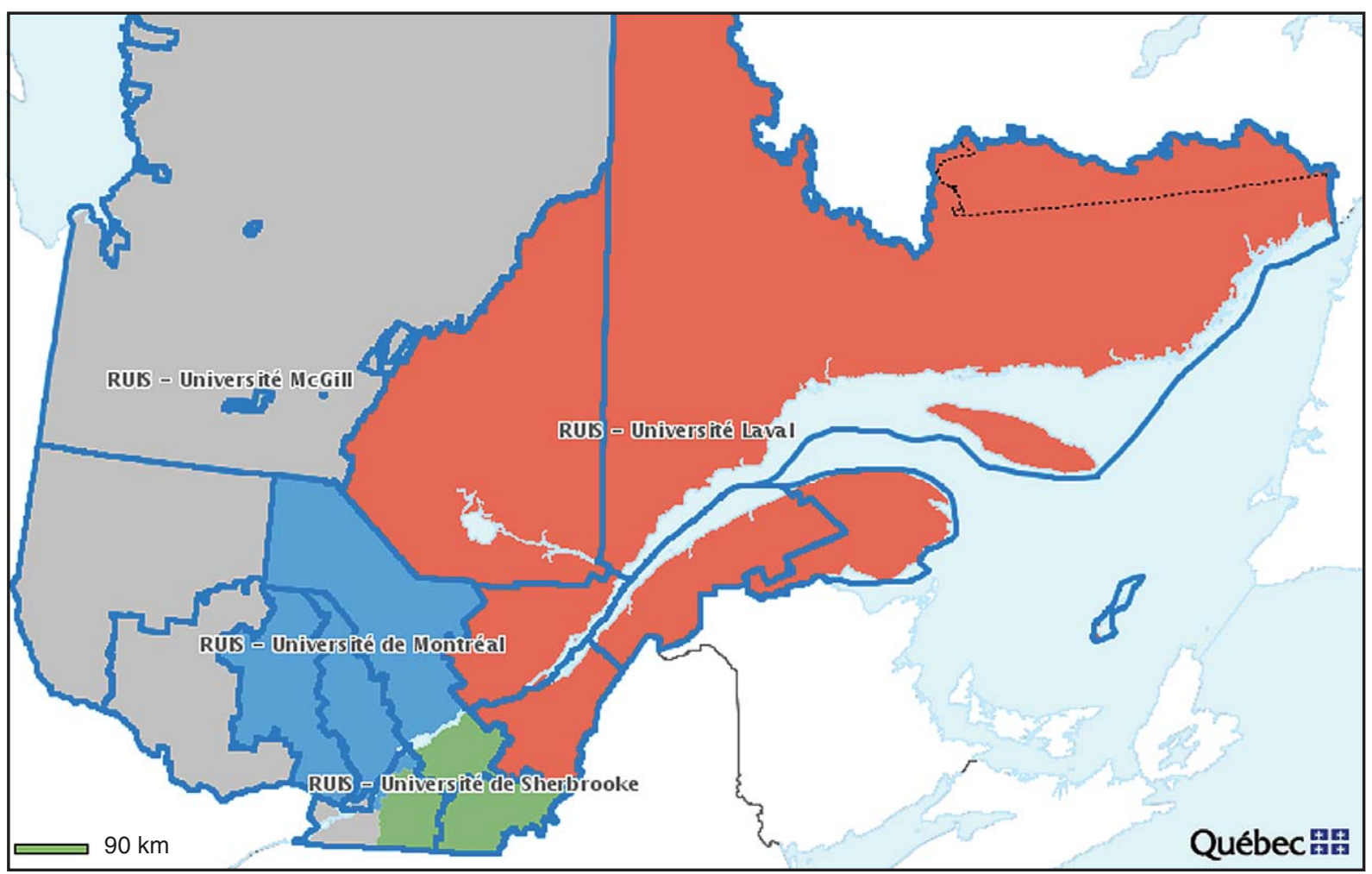

Fig. 1. Geographic distribution of the 4 RUIS in Québec. The region identified "RUIS - Université Laval" is covered by the Eastern Québec Telepathology Network. (Reproduction authorized by the "ministère de la Santé et des Services sociaux, (C Gouvernement du Québec, 2011”.)

inhabitants $/ \mathrm{km}^{2}$. The coordination of health care in this region is the responsibility of 6 health authorities.

In 2004, the Laval University RUIS created a telepathology project team tasked with performing a survey exploring and evaluating specific needs for telepathology in its remote regions. This survey revealed that, due to the lack of consistent pathology coverage in several smaller community hospitals, certain surgeries were required to be postponed, several patients were required to transfer to regional hospitals and two-step surgeries had to be performed when a frozen section was needed and no pathologist was available on site. This situation also proved to be a major hurdle in the recruiting of young surgeons trained in centers where access to an expert pathologist is never an issue. Furthermore, it was clear that younger pathologists in early practice felt insecure and were often reluctant to work alone because of the difficulty in rapidly obtaining a second opinion from a colleague. Practicing pathologists complained that they could hardly be absent without disturbing the surgical unit. In this context, the Laval University RUIS decided to launch the Eastern Québec telepathology project aimed at improving medical care by providing improved pathology coverage. Recent literature indicates that telepathology may be instrumental in reforming the health care system and improving the quality of care [2]. Studies performed in Québec also indicated that community hospitals were more likely than University hospitals to benefit from telepathology in terms of recruiting and support for surgeons and the community $[1,4]$. Therefore, this project was designed to provide strong support for remote communities. The general aim of the project was to encourage pathologists in a region to share their expertise to ensure consistent frozen section and rapid consultation coverage. However, the network also allows all pathologists in all regions to collaborate.

The Québec Ministry of Health and Canada Health Infoway agreed to financially support this innovative 
initiative with the objective of providing the population with uniform pathology services. The project is particularly timely because of the reports of two recent commissions of inquiry in Canada recommending the deployment of telepathology to help provide better professional support to pathologists and improve the quality of care in Canada [3, 5]. Requests for proposals, a call for tenders, contracts, physician fees agreement, a request for legal opinion and a choice of technologies were completed between 2008 and 2009. Deployment began in January 2010. A little more than one year later, the implementation and training of technical and medical staff are nearly complete and the network is most appreciated by pathologists and surgeons who began telepathology activities. In the course of implementation, a number of challenges arose which, while not threatening the deployment, nevertheless required a strategy to insure that the pace of the implementation was maintained. The objective of this paper is to share our experience on a number of these key challenges.

\section{Methods}

The aim of the Eastern Québec telepathology project is the creation of a network providing improved pathology coverage for the region of the Laval University RUIS. This is a "patient-oriented" project in which all surgeons and pathologists in this region are to have access to both frozen section diagnostic service and second opinions anywhere and at any time. The ultimate goal is to avoid unnecessary patient transfers to regional or University hospitals. Each hospital of the network is equipped with a whole slide scanner, a macroscopy station, two videoconferencing devices and a viewer and a case management and collaboration solution (Fig. 2). The slide scanners selected by the project team are Nanozoomers (Hamamatsu Photonics, Shizuoka Prefecture, Japan), of which 8 are the HT model (210 slides) and 13 are the RS model (6 slides). The macroscopy station selected is the PathStand 40 (Diagnostic Instruments, Sterling Height, USA) and the videoconferencing system is the PCS-XG80DS Codec (Sony, Minato, Tokyo, Japan) equipped with a drawing tablet Bamboo CTE-450 K (WACOM, Otone, Saitama, Japan). Those equipments were obtained from Olympus Canada. Inc., (Markham, Canada). The viewer and case management and collaboration system selected is $\mathrm{mScope}$ (Aurora Interactive
Ltd., Montreal, Canada). All hospitals in the province of Québec are linked together by a private, dedicated information network which ensures confidentiality and avoids use of the Internet (RTSS: réseau de telecommunications sociosanitaire). The project has been implemented in all 21 sites, of which 6 are devoid of a pathology laboratory. Of the remaining 15 sites, two have no pathologists, 6 have one pathologist and 7 have two pathologists.

Each of the 21 sites was visited by the project team prior to the deployment in order to meet the local medical (surgeons and pathologists), technical (informatics and biomedical) and administrative teams. The objective of these meetings was to better understand the needs, provide project information and identify potential locations for the equipment. A second visit was performed one year later in each center, after deployment. This second visit allowed the project team to gather invaluable information regarding the challenges met in the course of implementation.

\section{Results}

Several Eastern Québec pathologists have begun using the implemented telepathology system. Essentially, the activities include consultations between pathologists, remote grossing assistance, remote frozen sections and primary diagnosis of current cases. Preliminary data on the use of telepathology in the Laval University RUIS region is provided in Table 1 and confirms the enthousiasm of pathologists and surgeons at using the technology. Table 2 shows statistics for the time required for some initial frozen sections. The initial tests were performed in hospital 1 in November 2010 and activities began in hospital 2 in April 2011. The process for frozen section diagnosis via telepathology was intended to allow pathologists and surgeons to follow the same steps as if they were working in a single hospital. However, since the surgeon and the pathologist are in two different hospitals, certain steps in the process had to be adapted. Namely, the day before the surgery, the referring surgeon must select the cases for which a frozen section is required. These cases are accessioned at the referring center and the consulting pathologist receives an e-mail requesting him to access $\mathrm{mScope}$ to view the case list and the clinical history of each patient. The day of the frozen section, the consulting pathologist can view the 


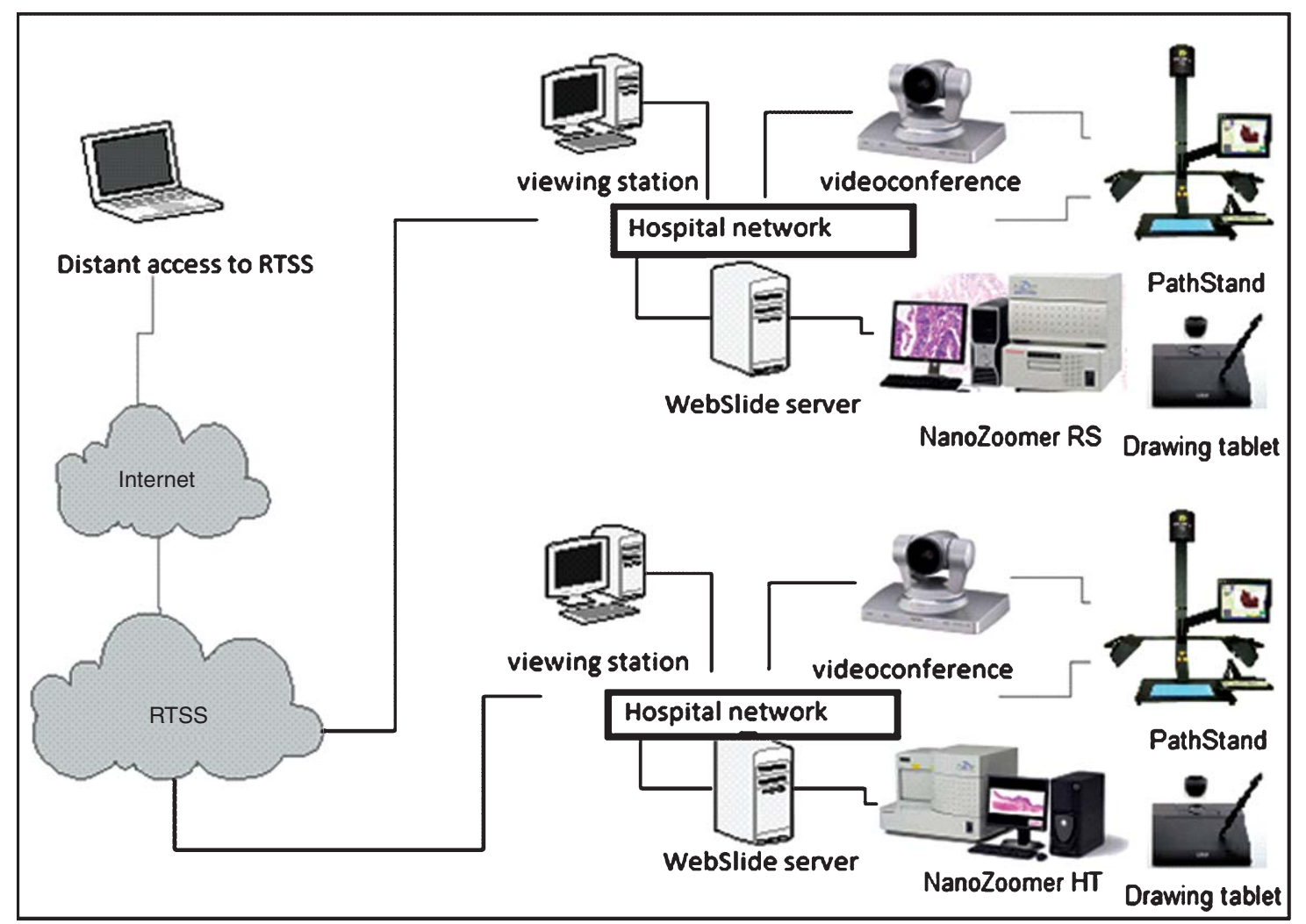

Fig. 2. Equipment provided to the 21 hospitals participating in the Eastern Québec telepathology project (RTSS: Réseau de télécommunications sociosanitaire).

Table 1

Preliminary report on number of analyses performed by telepathology in the Eastern Québec telepathology network between September 2010 and June 2011

\begin{tabular}{lr}
\hline Primary diagnosis of cases & 829 \\
Gross images for diagnosis & 500 \\
Consultations between pathologists & 95 \\
Frozen sections & 72 \\
Grossing assistance & 32 \\
Immunohistochemistry & 3 \\
\hline
\end{tabular}

Table 2

Time required to perform frozen sections

\begin{tabular}{lcc}
\hline & Hospital 1 & Hospital 2 \\
\hline Frozen sections & 16 cases & 36 cases \\
Time required & $26.7 \min (17-38)$ & $19.8 \min \left(8^{*}-36\right)$ \\
Macroscopy & $5.6 \min (3-14)$ & $6.2 \min (1-17)$ \\
Section & $9.8 \min (6-14)$ & $5.5 \min \left(1^{*}-12\right)$ \\
Slide Scanning & $2.6 \min (2-4)$ & $2.7 \min (1-6)$ \\
Access to image & $2.8 \min (1-8)$ & $1.4 \min (0-7)$ \\
Interpretation & $2.1 \min (0-9)$ & $3.4 \min (1-11)$ \\
\hline
\end{tabular}

* In cases of multiple specimens for a single case. specimen via the videoconferencing system in order to discuss it with the surgeon, technician or pathology assistant at the referring hospital. The consulting pathologist can also indicate precisely were to ink or to cut using a Drawing tablet (Bamboo WACOM). Once the section is ready and the slide has been scanned, the consulting pathologist examines the digital slide image within mScope, makes his diagnosis and calls the surgeon to communicate his opinion. The telepathology system allows the consulting pathologist to either dictate a report into the mScope case and assign it to a secretary of his choice to be typed or type the report into mScope himself. Once the report is complete, a PDF file is generated and the referring surgeon receives an E-mail confirming that the case is completed and that a report is available. The only limitation when comparing this process to one wherein the pathologist is on site is the inability of the pathologist to palpate the specimen. Our experience to date indicates that the time required for frozen section diagnosis via a telepathology system linking the operating room of one hospital 
to a pathology laboratory in another hospital is slightly longer than that required in the same hospital because of the time required for scanning and transfer to the server (Table 2). Furthermore, to date, a $100 \%$ concordance has been found between diagnoses made via telepathology on frozen sections and those obtained using a microscope on the paraffin control.

Another important activity enabled by telepathology is the ability for a pathologist to quickly and easily request a second opinion from a colleague. The system allows a referring pathologist to solicit an opinion from any other pathologist in the network. Similarly, the consulting pathologist can either accept or refuse to read the case or can redirect the case to a more appropriate colleague. Furthermore, the pathologist may dictate and assign the report for transcription or type his report which will be made available to the referring pathologist who is automatically notified by email that the report is completed and available within the system.

Basically, thus far, we have found that the major challenges encountered in the implementation of this network were related to change management. More specifically, the main challenges identified to date have been:

1) Although the surgeons practicing in the 6 hospitals devoid of a pathology laboratory and the two devoid of pathologists are motivated by the potential of the technology, they must become accustomed to requesting services that have been unavailable for many years. Indeed, these surgeons became accustomed to either transferring patients or postponing surgeries when a frozen section was expected and the pathologist was absent. They must now adapt to a new reality where the pathology coverage is available regardless of the presence of the local pathologist.

2) The network was required to adapt to changing situations occurring during the course of deployment, such as the relocation and retirement of pathologists. In one situation, the only pathologist of one of the hospitals of the network (called here the referring hospital) left as the implementation was beginning. However, one of the authors (SL), a pathologist practicing in a laboratory located more than 200 kilometers from the referring center (called here the consulting hospital), volunteered to cover the frozen sections. The expected interruption of the frozen section coverage was therefore avoided and the surgeons as well as technicians of both centers were satisfied because their activities remained unchanged. Indeed, in such a situation, without telepathology solutions being made available in this referring hospital, the surgeons would be afraid of not having frozen section coverage for an indeterminate period of time, the technicians of the referring hospital would be afraid of losing their jobs because of the reduced activity in the laboratory and the technicians of the consulting hospital would fear an increased workload because of their limited resources.

3) This unique network combining centers with or without laboratories required the development of innovative solutions. Since the 21 hospitals involved in this network have different Laboratory Information Systems (if they have any at all) and since pathologists may be requesting opinions from or supporting frozen sections for any of them, a versatile system allowing for the simple, efficient and reliable flow of information had to be developed. The videoconferencing and grossing station allow for real-time communication with the surgeons and/or pathology assistant and/or technician for either grossing of specimens or frozen sections. Furthermore, dictation and report format support via the viewing/case management solution allow for the rapid production of reports. Transcription may be assigned to any secretary on the network and reports may be integrated into any information system.

4) Pathologists are accustomed to reading glass slides and they must learn to feel secure making diagnoses on digital slide images. This is a major challenge for some of them because pathologists have been using a light microscope for over 150 years and are accustomed to this technology and there is currently no obligation for them to use telepathology. For that reason, even if most pathologists recognize that, as demonstrated in the literature, the quality of the images is comparable to glass slides and the concordance rate exceeds $95 \%$ [8, 9, 13], many remain reluctant to make primary diagnoses with this tool. For that reason, it is very important to develop a strategy to enable pathologists to adapt to this new technology. For instance, this can be achieved by including a validation period during which both glass slides and digital slide images are compared and by 
introducing physician fee incentives specifically for telepathology. Interestingly, this resistance to change varies tremendously between pathologists. For instance, even though the system was acquired primarily for frozen section and second opinions, several enthusiastic users adopted the system for a much larger portion of their case load including primary diagnosis (Table 1 ) while others were very resistant to using it at all.

5) The network must be developed within each region because University hospitals in Québec are unable to absorb any significant increased workload. Considering the shortage of pathologists in Canada, and Québec in particular, it is clearly preferable that community hospitals take an active part in the development of the telepathology network. Indeed, experts in University hospitals don't have enough time to both participate in the development and deployment of new technologies and respond to an increased flow of new second opinion consultations.

6) Surgeons and pathology staff must develop new working methods. Technicians in a pathology laboratory have a specific task definition. With the addition of a telepathology system, these tasks may change. In one specific hospital of the network, the pathologist and surgeons were accustomed to meeting early in the morning to agree on potential frozen section cases. The pathologist of this hospital left recently and the chief technologist was mandated to take his place at these morning meetings, increasing her workload and compromising her compliance to the new technology. Efforts were made to involve the surgeons in the identification of potential frozen section cases and meetings were organized to better coordinate the activities between surgeons of the referring hospital and the remote consulting pathologists.

7) Technicians in hospitals without a pathology laboratory have limited experience with histology techniques. In fact, both the self-confidence of the technologist and the mutual confidence between the technician of the referring hospital and the consulting pathologist must be developed. To achieve this goal, work has to be done to introduce and control uniform techniques and to encourage technicians and pathologists of different hospitals to work together. To date, in the Eastern Québec telepathology project net- work, a common staining procedure has been adopted and technicians of referring centers are being trained in laboratories with whom they will most likely collaborate via telepathology. This allows the referring technicians and consulting pathologists to develop a personal relationship and secure mutual confidence. Certain surgeons were also interested in participating in telepathology training along with the technicians in order to develop closer relationships with the pathologists.

\section{Discussion}

The Eastern Québec telepathology project is currently the most ambitious telepathology project in Canada [16] and ranks among the most important in the world in terms of both the number of sites and geographic coverage. Our experience confirms that telepathology helps to improve the quality of health care in remote regions, particularly in oncologic surgery. Our experience to date with the use of telepathology to cover frozen sections shows that the time required compares favorably with the current situation in those remote hospitals and with data from literature. Indeed, whereas in one hospital, an average of 19.8 minutes were required to complete the analysis, including 6.2 minutes of macroscopy, a recent article showed that it took 15.7 minutes without macroscopy [8]. Furthermore, our experience shows that pathologist performance increases rapidly after only a few cases.

Telepathology may prove useful to counter the shortage of pathologists, to provide services not available in remote communities and to support pathologists working alone. As in other parts of the world [10], Canada is facing a major shortage of pathologists and, in Québec, even University centers are inappropriately staffed. The reasons for the shortage are multiple and similar across Canada and telepathology may not only help to bring pathology coverage in communities with a lack of pathologists but may also render the specialty more attractive to medical students. One of the major causes of the shortage is the lack of the specialty's exposure and profile. Whereas $7.6 \%$ of medical students manifest a certain interest in pathology during medical school, in Canada, less than 3\% eventually apply to the residency program [10]. Of the main reasons 
pathology is not chosen is the feeling that pathology is boring and repetitive and that the pathologist has little contact with other people [10]. Telepathology may help to enhance the profile of the specialty by being more technologically advanced and by allowing pathologists and surgeons to work together more closely and easily. Furthermore, telepathology may not only help to recruit young pathologists in University centers, but also in remote laboratories that have the same equipment and can participate in vitual case discussions with colleagues abroad.

Telepathology is a unique means of providing services not otherwise available in remote communities. Certain community hospitals do not have enough surgical activities to justify the presence of a full-time pathologist or even of a pathology laboratory. Without telepathology, pathology cases are either being examined by a part-time pathologist or sent to a remote laboratory, which significantly limits the access to frozen sections. Frozen sections are essential in the practice of surgical oncology. The surgeon may be interested to know the state of resection margins or to get a diagnosis on an incidental lesion in order to orient the type of surgery. In breast cancer, the surgeon needs to know during the course of the surgery whether a sentinel lymph node is positive for metastatic cancer in order to avoid a two-step surgery. In hospitals with a part-time pathologist, certain surgeries must be grouped on the days when the pathologist is present, which limits the flexibility of the schedule.

Our experience so far confirms that the most important challenge encountered in the course of the implementation of telepathology relates more to personnel change management than to the technology. Pathologists have been trained to work individually and telemedicine requires a more multidisciplinary and collaborative approach. In the context of a shortage of pathologists, it can be very difficult to convince some of them that collaborating with others will not result in an increased workload but rather in a more efficient distribution of the work between university, regional and community laboratories. A recent analysis of 29 projects supported by the Canada Health Infostructure Partnerships Program (CHIPP) by one of us (JPF) [14] underlines the need for organizational support to enable telemedicine to succeed in a community. Briefly, this study showed that the vision of the project must be shared by the different partners and include the stakeholders, there must be strong medical leadership, the implementation teams must be dedi- cated and experienced, users must be involved and the technology must be mature [14].

Finally, telepathology may be used to support pathologists working alone and ensure their retention in their community. Indeed, it is estimated that 10 to $20 \%$ of oncologic cases must be validated by more than one pathologist [6] and certain quality assurance programs require that $10 \%$ of cases be reviewed by more than pathologist [15]. It is clear that without telepathology, pathologists practicing alone do not benefit from this level support. Prior studies by two of us (JPF, MPG) showed that telemedicine technologies may help to attract physicians to and retain them in remote regions by contributing to better working conditions [7, $11,12]$. Briefly, it was shown that telemedicine could influence physicians' retention through four main factors: 1) access to continuing medical education; 2) access to specialized services such as a second opinion from an expert or a colleague; 3 ) possibility of sharing the workload and the calls to avoid rupture of service; 4) feeling of security because of reduced isolation.

\section{Conclusion}

The Eastern Québec telepathology network is successful and improves medical care to patients in this region. In the course of implementation, we encountered a number of challenges mostly related to change management, and which required innovative solutions. Our experience reported in this article may be helpful to any organization intending to implement a public health/patient-oriented telepathology project.

\section{Acknowledgments}

We want to thank Mr. François Boilard, project manager of the Eastern Québec telepathology project, for his kind collaboration at gathering different statistics about telepathology. We are also thankful to Mr Germain Aoun (Olympus Canada Inc) and Mr. Matthew Smith (Aurora Interactive Ltd) for the editing of the manuscript and to Mrs. Michèle Orain, research assistant, for the review of the literature.

Presented in part at the first meeting of the International Academy of Digital Pathology in Quebec city on August 3rd 2011. 


\section{References}

[1] Agence d'évaluation des technologies et des modes d'intervention en santé du Québec, Télépathologie: Lignes directrices et normes technologiques Revue de la littérature. Quebec government, (2008).

[2] R.L. Bashur, G.W. Shannon, E.A. Krupinski, J. Grigsby, J.C. Kvedar, R.S. Weinstein, J.H. Sanders, K.S. Rheuban, T.S. Nesbitt, D.C. Alverson, R.C. Merrell, J.D. Linkous, A.S. Ferguson, R.J. Waters, M.E. Stachura, D.G. Ellis, N.M. Antoniotti, B. Johnston, C.R. Doarn, P. Yellowlees, S. Normandin and J. Tracy, National telemedicine initiatives: Essential to healthcare reform, Telemed J E Health 15 (2009), 600-610.

[3] M.A. Cameron, Commission of inquiry on hormone receptor testing volume 1: Investigation and findings, Government of newfoundland and labrador office of the Queen's printer department of government services, (2009).

[4] Canada Health Infoway. http://www.infoway-inforoute.ca/ lang-fr/about-infoway/news/news-releases/613-uhn-establish es-first-telepathology-system-in-ontario 1, (2010).

[5] Commission of Inquiry into Pathology Services at the Miramichi Regional Health Authority, Department of Health, Province of New Brunswick, Fredericton, New Brunswick, Canada, (2009).

[6] M. Dietel, T.N. Nguyen-Dobinsky and P. Hufnagl, The UICC Telepathology Consultation Center. International Union Against Cancer. A global approach to improving consultation for pathologists in cancer diagnosis, Cancer 89 (2000), 187-191.

[7] J. Duplantie, M.P. Gagnon, J.P. Fortin and R. Landry, Telehealth and the recruitment and retention of physicians in rural and remote regions: A Delphi study, Can J Rural Med 12 (2007), 30-36.

[8] A.J. Evans, R. Chetty, B.A. Clarke, S. Croul, D.M. Ghazarian, T.R. Kiehl, B. Perez Ordonez, S. Ilaalagan and S.L. Asa, Primary frozen section diagnosis by robotic microscopy and virtual slide telepathology: The University Health Network experience, Hum Pathol 40 (2009), 1070-1081.

[9] M.A. Fallon, D.C. Wilbur and M. Prasad, Ovarian frozen section diagnosis: Use of whole-slide imaging shows excellent correlation between virtual slide and original interpretations in a large series of cases, Arch Pathol Lab Med 134 (2010), 1020-1023.

[10] J.C. Ford, If not, why not? Reasons why Canadian postgraduate trainees chose-or did not choose-to become pathologists, Hum Pathol 41 (2010), 566-573.

[11] M.P. Gagnon, J.P. Fortin and R. Landry, Telehealth to support practice in remote regions: A survey among medical residents, Telemed J E Health 11 (2005), 442-450.

[12] M.P. Gagnon, J. Duplantie, J.P. Fortin and R. Landry, Exploring the effects of telehealth on medical human resources supply: A qualitative case study in remote regions, BMC Health Serv Res 7 (2007), 1-9.

[13] C.L. Hitchcock, The future of telepathology for the developing world, Arch Pathol Lab Med 135 (2011), 211-214.

[14] L. Lamothe and J.P. Fortin, Gestion du changement et L'intégration des technologies dans le continuum de soins: Rapports finaux. Ottawa : Santé Canada, Programme des partenariats pour l'infostructure canadienne de la santé (PPICS), (2007).

[15] R.E. Nakhleh, L.G. Bekeris, R.J. Souers, F.A. Meier and J.A. Tworek, Surgical pathology case reviews before sign-out: A College of American Pathologists Q-Probes study of 45 laboratories, Arch Pathol Lab Med 134 (2010), 740-743.

[16] Quebec telepathology project aims to be the largest in Canada, Healthcare Technology 15 (2010), 13.

[17] Réseau Universitaire Intégré en Santé de l'Université Laval, Plan de développement de la télésanté au RUIS-UL, 2005.

[18] Statistics Canada, Canada's population estimates: http://www. statcan.gc.ca/daily-quotidien/110622/dq110622a-eng.htm, 2011 


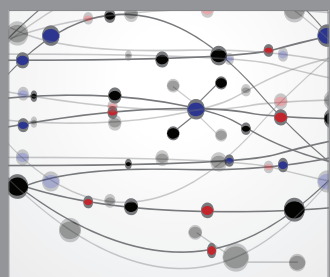

The Scientific World Journal
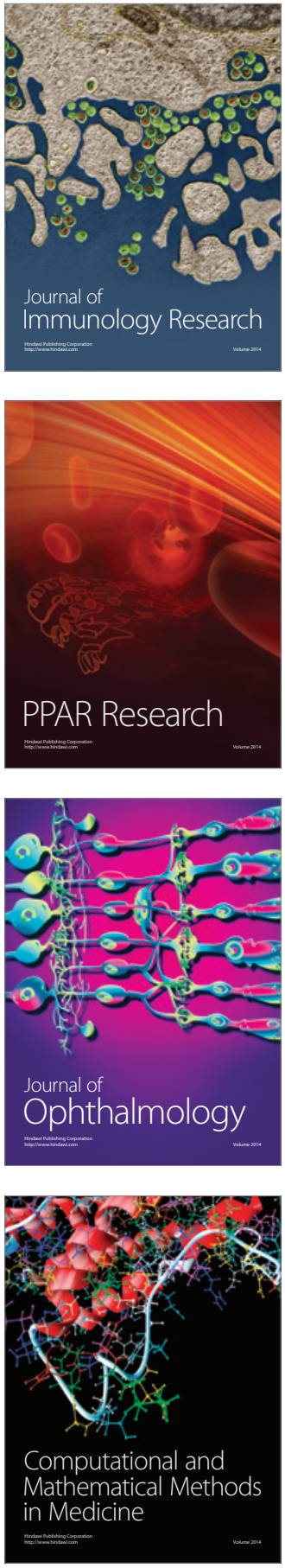

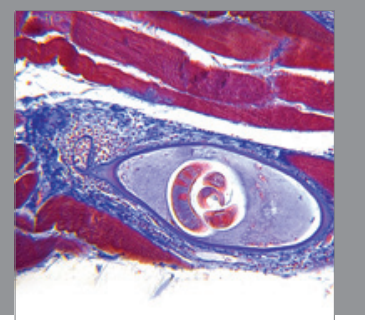

Gastroenterology

Research and Practice
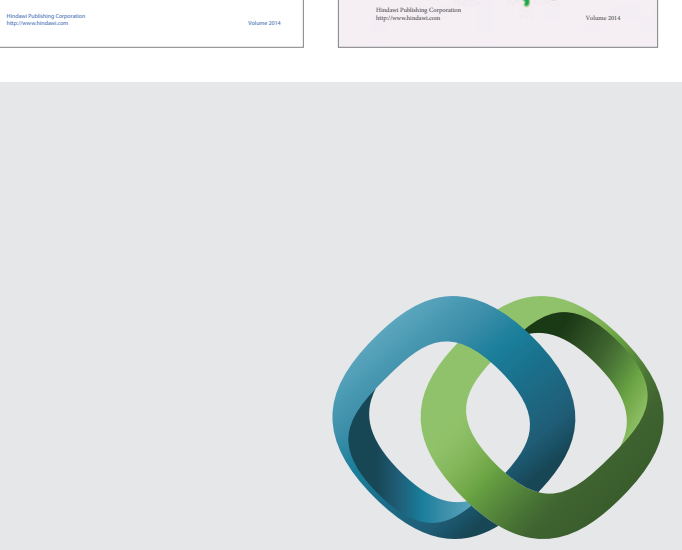

\section{Hindawi}

Submit your manuscripts at

http://www.hindawi.com
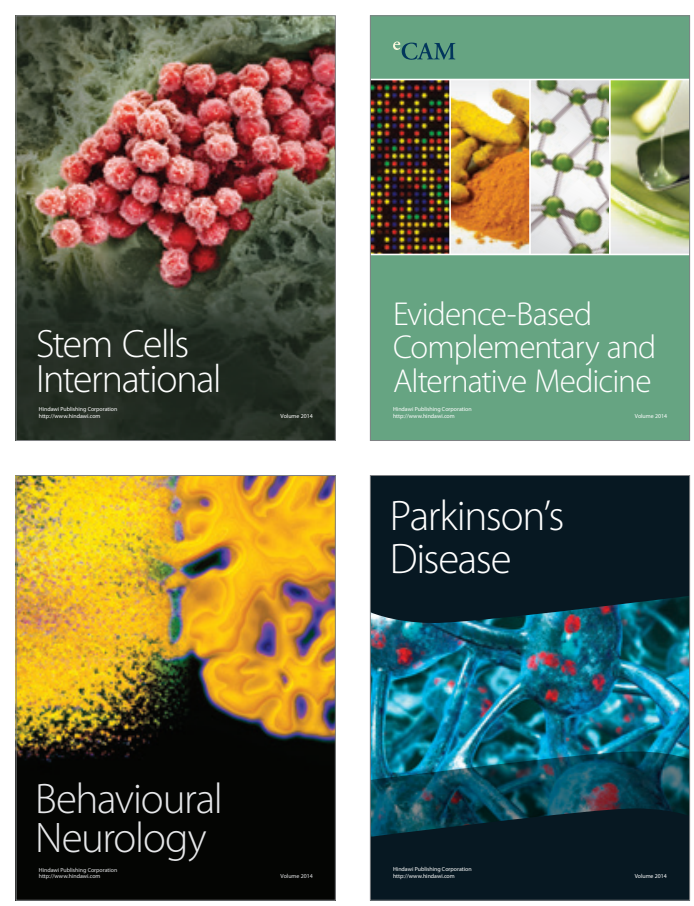

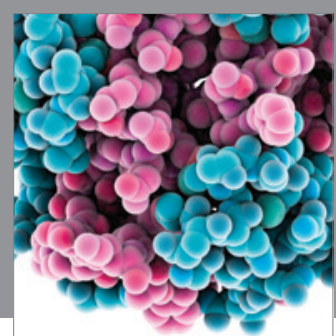

Journal of
Diabetes Research

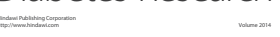

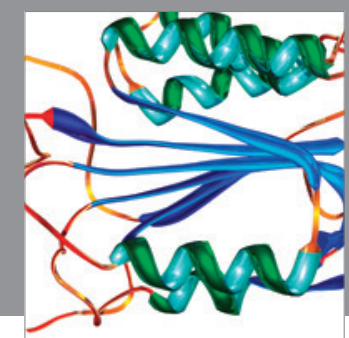

Disease Markers
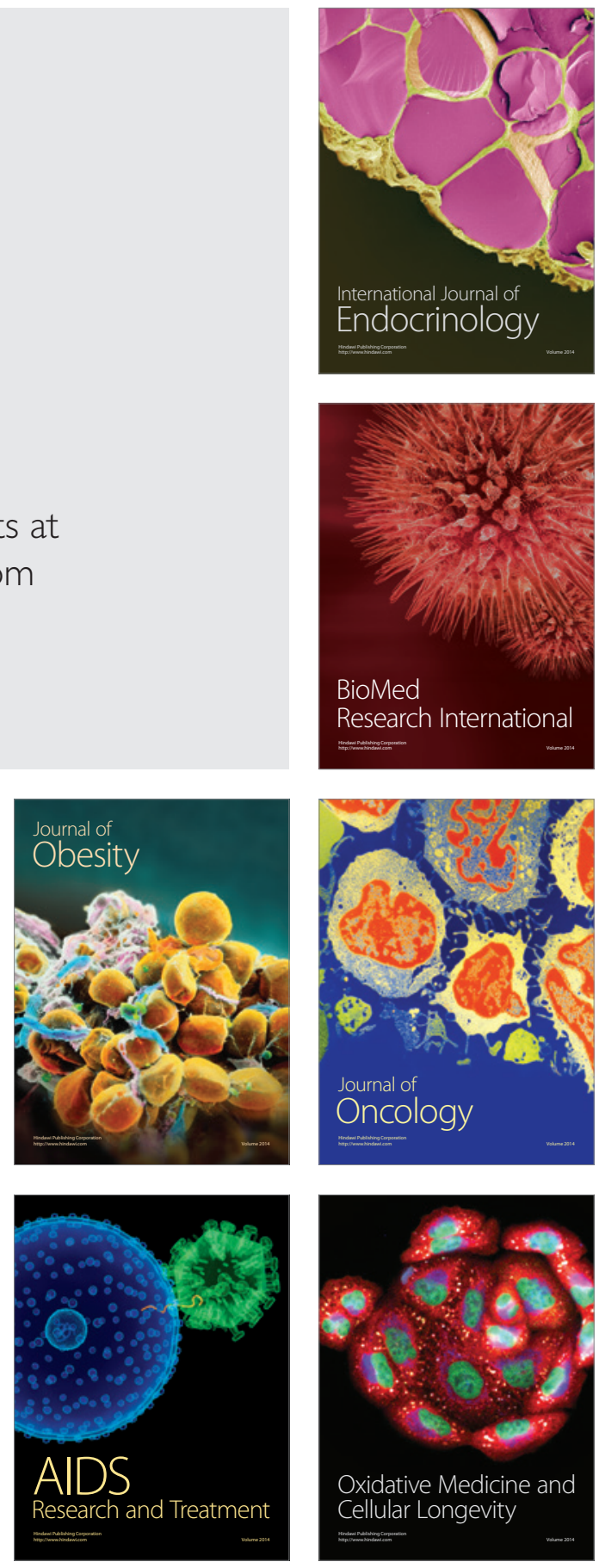